\title{
Entrevista con Peter Burke
}

\section{Burke: historia cultural, historia de los conocimientos}

El historiador inglés Peter Burke, nacido en 1937 y educado inicialmente por los jesuitas, estudió en Oxford. Ha sido, hasta su reciente jubilación, profesor de historia cultural en la Universidad de Cambridge así como miembro del Emmanuel College. Italianista de vocación itinerante desde muy joven $-\mathrm{y}$ gran políglota por afición-, ha dado cursos por doquier, como un entusiasta ilustrado que rehuye la repetición de paisajes y cualquier enclaustramiento. Siempre ha luchado cautelosamente contra esa constatación suya de que la comunidad intelectual, pese a tantos congresos internacionales, es más bien una confederación de «subculturas locales». Sus numerosos libros, de muy diversos planteamientos, han sido traducidos a más de veinte lenguas, y una cifra similar es la de los que se han vertido al castellano.

Ante una obra tan variada como la suya cabe plantearse, de antemano, la pregunta sobre la posible armonía de sus intereses, sobre su disparidad aparente. Suele decirse que Burke ha pasado, a lo largo de una larga trayectoria investigadora, de la historia social de la cultura a la historia cultural de los fenómenos sociales. Pero en cierta medida esto no es sino un juego de palabras, sobre todo si se tiene en cuenta, por ejemplo, que dos libros, como La cultura popular en la Europa moderna y Formas de historia cultural, respectivamente de 1978 y de 1997, tienen muchos contactos: el mundo del carnaval, lo bufo y la inversión o subversión cómica, el lenguaje de los gestos, la contraposición misma entre lo culto y lo popular, la idea en fin de cultura y sus manifestaciones.

Burke ha trabajado sobre aspectos generales o singulares con proyección general de la época renacentista, de un modo pendular o cíclico. Ha escrito tres libros sobre la vertebración entre cultura y sociedad al inaugurarse la modernidad en Italia, destacadamente en su «burckhardtiano» El Renacimiento italiano. Es un libro ya clásico que habla de las artes en su medio más específico (el mundo de los creadores, su organización y sus extravagancias, los patronos y el mercado, el uso de las artes, los problemas del gusto, la iconografía), y, paralelamente, analiza la colectividad y su entramado, las concepciones cosmológicas, sociales y homocéntricas, por cierto haciendo una exploración a los Países Bajos y al Japón para ponerlo todo en perspectiva.

Su investigación sobre las formas culturales modernas se ha doblado siempre de otras líneas de trabajo, hasta el punto de ofrecer dos bellas monografías, Montaigne y, sobre todo, Los avatares de 'El cortesano', que abordan a autores singulares de la acción civilizadora del Renacimiento, tanto por sus modos de vivir como por sus modos de decir: Castiglione el refinado se hizo oír a lo ancho de Europa, proyectando muchas imágenes del nuevo individualismo, y el jugoso Montaigne, que escribió parte de sus Viajes en italiano, se forjó en el latín reno- 
vado de entonces para crear el sentimiento de uno mismo y la imagen de su autonomía en una lengua nacional ya muy bien engrasada. Pero el culto estilo de ambos no puede en absoluto desligarse de la cultura popular de entonces, con ésta se complementan y enriquecen, pues son escritores asimismo del cuerpo. Sus respectivos ecos sirven además para captar mejor los cambios educativos y mentales del Quinientos, pues ambos precisamente usaron conceptos poco abstractos, manejables por el historiador, y más aún si es tan abierto como este inglés apasionado por El cortesano. Precisamente, Burke mostraba cómo se traslucía la italianofobia del Barroco en una recepción tardía, distorsionada ya, de Castiglione; hecho que podría emparejarse con el odio a Montaigne por el gran dogmatismo del siglo XVII. Ambos aspectos se opondrían a las preferencias laicas y a las mismas «Luces» de su autor.

Burke ha redactado también, para la serie de historia europea diseñada por Le Goff, un originalísimo El Renacimiento europeo. Centros y periferias; y el subtítulo es muy indicativo de su atención plural a ese proceso expansivo que significa la modernidad. Más aún, siempre se ha preocupado por señalar que cierta historia de la vida cotidiana, desarrollada en estas décadas últimas o la revolucionaria historia de las mujeres eran modos de reaccionar contra una historiografía a gran escala de las tendencias sociales, pero que no era capaz de acercarse a los individuos. Por lo demás, él ha facilitado la actual integración de las historias política y social, como sucede en La fabricación de Luis XIV, análisis de la invención de la moderna realeza y de su presencia tan llamativa (y tan denunciada desde 1789). Y a la par ha renovado el viejo problema, planteado entre otros por Duby o Guriévich, de las relaciones entre la cultura popular y la elaborada, no sólo en multitud de textos sino también al analizar -en una especie de microhistoria, nunca olvidada en sus debates-, el papel dinamizador e impositivo de las elites en la Venecia y Amsterdam de entonces, dos ciudades del poder, de la imprenta y de la comunicación, de modo tal que expone ahí la última mirada del Mediterráneo a la aurora de la moderna riqueza atlántica, representada por la pujanza holandesa.

Más tarde se ha dedicado al estudio de la recopilación y difusión del conocimiento en la moderna Europa, que tiene mucho que ver con la efervescencia renacentista, luego doblada por la Ilustración. Y lo ha hecho directamente examinando determinados controles comunicativos, así en la educación verbal: Hablar y callar. Funciones sociales del lenguaje a través de la historia es un libro excelente y muy ajustado a su capacidad para percibir, en las palabras y sus variantes nacionales e históricas, ciertos procesos fundamentales, como son el peso del latín en la modernidad o ciertas dosificaciones del lenguaje y el silencio, con todas sus variedades (cálidas o no, agresivas, templadas, íntimas, excluyentes) al analizar la proyección -a través de los mecanismos de comunicación-, de los distintos modos 
de expresarse. O bien se ha interesado por la mirada, analizando, quizá con menos originalidad pero sí con poder sintético, el uso de la imagen como documento en la historia, de todos los modos posibles; nos referimos a Visto y no visto, un libro, eso sí, bello, plural y bien ilustrado, pues el autor nunca ha omitido lo que la historia del arte -desde Warburg, Saxl y Panofsky hasta Wind y Gombrich- ha supuesto para entender la cultura.

Ahora bien, si Burke parece muy inglés -dado su registro tan controlado de los hechos culturales-, nunca se cierra a otros mundos. Antes al contrario, no olvida ni la ciencia china (Needham), ni los estudios de Giedion sobre la mecanización, ni los textos latinoamericanos (de Freyre, León Portilla, Wachtel, Gruzinski o su propia mujer M. Lúcia Pallares-Burke, brasileña), ni a Américo Castro, ni tampoco el Orientalismo de Said. Además él ha leído a fondo y comentado la historiografía francesa, se ha interesado toda la vida por las formas más innovadoras de la historia actual. Son muy llamativos, de hecho, dos libros suyos de reflexión, como Sociología e historia, y más aún La revolución historiográfica francesa -que va desde Febvre y Bloch hasta Braudel, Le Roy Ladurie, Foucault, Agulhon, Corbin, Nora o Bourdieu-, o la obra dirigida por él, Formas de hacer historia, que recoge trabajos de Joan Scott, G. Levi, R. Darnton, I. Gaskell o R. Porter, entre otros, y que barre muchas perspectivas historiográficas, tanto desde el punto de vista del método como de los objetos, sucesos, formas y articulaciones sociales que ellas abordan.

Esta obsesión omnímoda vuelve ordenadamente en ¿Qué es la historia cultural?, de 2004, en donde analiza la gran tradición de Burckhardt -que, a su juicio, nunca habría desaparecido- o de Huizinga. En un medidísimo balance, habla de la antropologización de la historia (que asomaba ya en La revolución historiográfica francesa), se detiene en un cuarteto tan significativo como Bajtin, Elias, Foucault y Bourdieu, en los estudiosos de la lectura y la representación, en la historia del cuerpo o de la cultura material, para ir luego dando vueltas conceptuales bien de mano de Certeau y Chartier, bien de los historiadores de la locura, del deconstruccionismo, de la historia de la percepción, de las emociones y de la violencia (eso que proponía Nietzsche en La gaya ciencia). Y todo ello sin olvidar, críticamente, que acaso la historia social pasará su factura a no tardar; si bien mantiene la esperanza de que la riqueza de los nuevos interrogantes culturales sea reintegrado en un futuro discurso histórico.

Y de toda la producción de este polifacético historiador, su amplia Historia social del conocimiento, de 2000, es la que tiene que ver directamente con la sociología de la ciencia. Aunque en absoluto se encierre en este campo historiográfico, sus análisis pueden servir para valorar ciertos aspectos de la difusión de la cultura científica, tal y como se forjó entre los siglos XVI y XVIII; por ello, nos 
detendremos en este libro, para dar por añadidura una imagen más precisa de su trabajo.

Como otras obras suyas, su Historia social del conocimiento está severamente estructurada, quizá frustrando al inicio las expectativas de un lector de ensayo «continental», más arropado por el magma Weber, Cassirer o Gramsci, Mauss, Lévi-Strauss o Foucault (a quienes, por cierto, él cita a menudo). Sin embargo, aunque lo encauce con un plan inicial férreo -los nuevos intelectuales modernos, las instituciones, los lugares del conocimiento y las formas de clasificación de éste-, formula de hecho luego, de un modo progresivamente más suelto, problemas como el del control religioso y político de los distintos saberes, las relaciones con el mercado (con especial insistencia en la revolución de la imprenta), o, finalmente, el acceso al conocimiento y el mundo del lector. Es decir, su recorrido va desde la emisión del saber con sus nuevas junturas, pasando por los mecanismos de comunicación y filtraje, hasta llegar al receptor, que es una persona nada pasiva en su libro. Por añadidura, en el capítulo de cierre, sobre la fiabilidad del conocimiento, recuerda que los nuevos escepticismos históricos pueden combatirse con teorías y prácticas textuales o sociales ajustadas; esto es, mediante pruebas, instituciones y demostraciones rigurosamente explicitadas.

Ahora bien, su clasificación del conocimiento se ve abordada atractivamente para el historiador de la ciencia, y también para el arqueólogo de la cultura. Veámoslo. La transmisión del saber en su conjunto, en particular cuando van a irrumpir las ciencias nuevas, estuvo supeditada en parte a una compleja, rara y para nosotros confusa clasificación, fuese ésta arborescente, pansófica, o «curiosa». Pero si se percibe como un todo en donde se entrecruzan el currículo universitario, la organización de una biblioteca y las enciclopedias, entonces puede verse esa transformación con otra luz. Las carreras (los cursos, pues) y las facultades (a la vez, habilidades y grupos corporativos) van a mutarse desde el siglo XVI. A las tres más cuatro artes tradicionales, escalonadamente enseñadas con un conglomerado filosófico aristotélico, les siguen las tres facultades altas (teología, derecho, medicina); pero a estos diez elementos básicos se les sumarán nuevas disciplinas (así la historia o la química), y sobre todo el cuarteto matemático se ensanchará, al tiempo que la filosofía natural se ve fragmentada. Pero es que, recuerda Burke, el sistema de las disciplinas se reforzó al principio con el orden de los libros, esto es, con el orden de las bibliotecas, de modo que éstas materializaban -física y espacialmente- la clasificación del propio currículo; al poco tiempo, sin embargo, la fuerza de «lo impreso» fue distorsionando el ordo librorum, de modo que su presencia no académica (como sucedió con muchas ciencias nuevas) fue cuestionando el lugar que la tradición fijó. Y asimismo, en el siglo XVII y el siguiente, el cambio repercute en las enciclopedias, que significaban tanto el currículo 
mismo, el ciclo disciplinar, como los libros de síntesis plurales de que se sirven el estudiante o el estudioso. En el siglo XVI se imprimen todavía compendios de los siglos XII y XIII, pero al tiempo se buscan muchas otras recopilaciones, de mil tipos distintos, y se especula sobre un ordenamiento total, matemático o no, que sea una especie de revelación del conocimiento. Hay gran desconcierto, pues, seguido de afanes renovadores. Todo ello se ve bien en el siglo XVII, con Naudé, que busca otras «facultades» y análogamente otras «secciones bibliográficas»; en Alsted, que busca la arqueología de los «sistemas del pasado», ya en desuso, mientras ofrece las líneas de una enciclopedia universal remozada por completo; o en Leibniz, sabio total y bibliotecario de Wolfenbüttel, cuando afirma, en 1679, que «una biblioteca debería parecerse a una enciclopedia», y cuando propone una secuencia de facultades formada por las tres nobles pero seguida -en un plano similar- por filosofía, matemática, física, filología, historia y miscelánea, de acuerdo con las novedades bibliográficas y eruditas de esa centuria ya muy acelerada intelectualmente.

En fin, en esta obra de Burke, con la abundancia de datos, lo prismático de sus ejemplos, los cambios de perspectiva siguiendo el mapa del mundo (Europa, América, Asia), las minas de documentación que nos ofrece -aunque seguramente él tenga una mayor capacidad verbal que visual y una mayor soltura expositiva y jerarquizadora que teórica-, vemos bien cómo se apoya en pormenores y enumeraciones y los dosifica hábilmente. Por cierto que una parte de su Historia social del conocimiento se centra en los libros de consulta que florecen en la modernidad, antes de despegar en el siglo XVIII, y él mismo no se retiene a la hora de contar el papel multiplicador que hasta sus títulos expresaban: catálogo, corpus o directorio, sí; pero también castillo, teatro, árbol, bosque, jardín, espejo, tesoro, mina de oro, itinerario, llave o médula. Parece revelador este listado, pues Burke es muy curioso y laberíntico, un apasionado de diccionarios y viejas relaciones.

A lo largo de este bosque suyo, de casi mil referencias bibliográficas, late la renovación italiana y europea que le ha venido ocupando toda su vida, y resurgen todos los temas de este neoilustrado: la superposición de la cultura selecta sobre la tradicional, los usos diversos del lenguaje escrito, el deslizamiento cultural desde Venecia hasta Amsterdam (cuyos cartógrafos e impresores revisa con penetración), los modelos de Castiglione o de Montaigne (comparando a éste con Montesquieu y a aquél con Burton), cuyas obras fueron lecturas intensivas suyas. Recuerda también a centenares de figuras menos repetidas, inglesas e italianas, así como españolas, holandesas y francesas, portuguesas y orientales, forjando nuevas preguntas sobre el pasado y su condicionamiento sobre el presente a través de nombres propios que siempre han sido sus mensajeros. Pero, como es propio de un historiador, señala con fuerza que, en el territorio del conocimiento, la historia de la modernidad no sólo se 
rastrea a través de las páginas de Bacon o de Vico (o las de sus comentaristas más teóricos), sino también estudiando mecanismos globales, críticos entonces, como sucede en ese momento de centralización, de creación del Estado y de la consiguiente formación de un conocimiento oficial, que supone una información generalizada que sirve, a la vez, de autocontrol y de espionaje.

Además de por las variadas culturas que adornan sin duda a Burke, su éxito seguramente esté basado en una claridad informativa moderna, densa y plural, y en una línea argumental bien aireada. Su presencia como autor es siempre tan discreta como eficaz, lo que se ajusta a su inclinación enciclopédica; y destaca su inusual respeto y atención por lo que dicen los libros de los que se surte. En los itinerarios tan vastos y sintéticos que ha venido presentando -cada vez más a menudo-, las referencias que proporciona son a veces fugaces y quizá no estén apuradas a fondo, sobre todo cuando tienen cierto aliento teórico, pero sí desde luego se ven generosamente escuchadas por él. Es cierto que el peso del concepto facilita que el discurso cuaje y se retenga, e impide su evanescencia. Pero Burke-con una modestia nada fingida-, ha contribuido a hacer comprensibles las innovaciones históricas y es un excelente evaluador de los conocimientos actuales, además de haber ensanchado el conocimiento del pretérito con sus propios y nuevos medios. Al culminar su carrera nos ofrece paseos diversos por un jardín sabio mostrando siempre una viveza y un equilibrio que pueden ser guías, hoy, para la mejor comprensión cultural.

Mauricio Jalón

Entrevista

Frecuentemente se dice que para entrar en el mundo de un autor es importante «ponerse las ropas» del tiempo. Recordando aquel trabajo sobre «egohistoria» [Essais d'egohistoire, París, Gallimard, 1987, ed. P. Nora] y en clave etnohistórica, ¿cómo ha sido su formación intelectual: quiénes han sido sus maestros, cuándo y dónde ha estudiado?

La historia externa es muy simple de contar; tal vez la historia interna lo sea menos. Estudié en Oxford, a fines de los años cincuenta, con un profesor muy joven; era su primer año de enseñanza, y su nombre es Keith Thomas. Él había sido discípulo de Christopher Hill, por lo que insistía en «mirar todo con ojo social». Luego, como estudiante de postgrado, mi profesor fue Trevor Roper, mucho más conservador, tanto metodológica como políticamente, y nunca mostró demasiado interés por mi investigación, aunque siempre hablaba muy bien de $s u$ 
investigación. Él daba clases en un estilo «conferencista»; luego, preguntaba si había alguna dificultad, y él mismo autorrespondía que seguramente no; acto seguido se despedía hasta el próximo mes.

En 1962, entré en la nueva Universidad de Sussex. Fue muy importante para mí cambiar de colegio; el primero había sido el tradicional St. John's College de Oxford, el segundo fue el nuevo St. Antony's College, y su importancia residía en que la mayoría de sus integrantes eran extranjeros: cincuenta estudiantes de postgrado y quizás solamente cuatro o cinco ingleses. Aquí mi gran amigo fue un ecuatoriano recientemente llegado de París, Juan Maiguashca (hoy profesor de Historia económica de América Latina en Toronto), discípulo de Chaunu, él fue quien me introdujo al mundo de Annales. Claro que yo había leído ya los libros de Braudel como estudiante, pero es muy diferente encontrarse con una persona de ese mundo, hablar todos los días con alguien que entendiera todo «desde dentro». Podría decirse que ingreso en el mundo de Annales de la mano de un discípulo latinoamericano de Chaunu.

¿Quiénes fueron sus «compañeros» a lo largo del camino de construcción de su oficio de historiador?

Tuve una experiencia muy importante para mí antes de ir a la universidad. En aquella época, en Inglaterra existía el servicio militar obligatorio y en mi colegio se estilaba realizarlo antes de comenzar los cursos, así es que con dieciocho años fui para Singapur por diecisiete meses a un regimiento local, allí había malayos, hindúes, chinos... ¿Cultura híbrida, no?

¿Fue allí donde comenzó su interés por conocer las distintas lenguas?

Ciertamente, también mi interés por los diversos estilos de vida, por las distintas mentalidades...

En 1962 era estudiante. ¿Cómo vivenció el mayo francés?

En aquella época yo era profesor en Sussex. Esta universidad tuvo a comienzos de los años sesenta la reputación de «universidad de izquierda» más por sus profesores que por sus estudiantes; por eso no tuvimos movimientos dentro de la Universidad como sí los hubo en otras universidades inglesas. En Sussex todo estaba permitido, nada era subversivo. Claro que era muy interesante seguir los acontecimientos en Francia, pero en aquella época no me tenían demasiada confianza, yo sólo tenía treinta años. Era el principio de una distancia cultural con los estudiantes, ya que comencé a ser profesor a los veinticinco años; aunque, por lo mismo, los estudiantes me parecían más amigos que alumnos. Después del 68 aparece «otra» generación. 
Retomemos la construcción de su oficio de historiador...

Mi experiencia más importante luego de la de Oxford, fue en mi nueva Universidad de Sussex, con ideologías de interdisciplinariedad. Allí trabajaba con sociólogos, con especialistas en literatura... Luego en los años sesenta, con el History workshop tuve los primeros contactos con historiadores sociales de izquierda, como Raphael Samuel. En 1967 fui a Princeton, un lugar maravilloso para hacer investigación, invitado por Lawrence Stone. Casi todos tenían veinte años más que yo. Allí hablé con Panofsky; pero él no quería oír hablar de la historia social del arte, sólo le interesaba la iconografía. En aquella época el Instituto para Estudios Avanzados lo integraban solamente matemáticos, físicos, historiadores del arte, y especialistas en el mundo clásico, pero también estaba Felix Gilbert estudiando el Renacimiento.

Después de Princeton, y de Sussex, en 1979 fui a la Universidad de Cambridge. Ahí había una gran ventaja: gente linda, más tiempo libre y una buena biblioteca; pero lo más importante intelectualmente fue cambiar de un ambiente donde todos pensábamos más o menos igual a otro mucho más crítico, donde era necesario defender todo nuevo abordaje. Por ejemplo, cuando intenté organizar un curso de antropología histórica con mi colega Bob Scribner, fue preciso esperar tres años. El Comité no lo aprobaba; decían siempre que era preciso hacer unas pequeñas modificaciones; finalmente, nos propusieron que el curso podría dictarse si suprimíamos la teoría. Creo que esto describe mi divertido itinerario de Oxford a Cambridge, vía Sussex.

A la manera de como aborda la Revolución historiográfica de 'Annales', ¿podría darnos una imagen de la historiografía inglesa?

Hoy la situación es más fluida. Cuando comencé a enseñar, la mayoría de los historiadores ingleses eran historiadores políticos (estamos hablando de los años sesenta). Luego, hubo un traslado hacia la historia social de la mano de un grupo de historiadores marxistas, el grupo Past and Present; pero había mucha desconfianza hacia la historia de las ideas, hacia la historia de la cultura, es decir, hacia una historia con conexiones teóricas. Claro que estaba el Instituto Warburg, pero había quedado aislado: una isla germánica y cultural, en un mar de empirismo inglés. Para muchos de mis colegas la historia cultural no tenía sustancia, ya que era y es muy importante, como dicen los ingleses, «tener los pies en la tierra».

En los años sesenta se evidencia un cambio, al menos en el área de la sociología y en otras disciplinas; existe un mayor interés por las ideas continentales, como por ejemplo las traducciones de Foucault. Pero fue recién en 1972 cuando El Mediterráneo de Braudel fue traducido al inglés, por iniciativa más norteamericana que inglesa (esto, hoy, parece increíble). En nuestros días, la situación es más interesante y más complicada: de un lado, un nueva generación lee a Braudel 
sin esa hostilidad para con Annales que mostró Elton; de otro lado, hay un movimiento global de reacción contra la historia social, la vuelta a la narrativa, a la historia política; esto implicaría hablar de una situación actual un poco confusa...

En este marco, ¿dónde ubicaríamos a Eric Hobsbawm y a E. P. Thompson? ¿Qué opinan ellos de esta manera de hacer historia?

No hay unanimidad. Claro que, ahora, casi todo el mundo respeta a Hobsbawm como un hombre de casi ochenta años que produce historia con gran penetración y estilo irónico... Pero, a pesar de eso, muchos historiadores ingleses piensan que Hobsbawm y Thompson son dogmáticos y rígidos. Esto es muy irónico, porque ellos se definieron en oposición a un marxismo rígido.

Tras haber realizado una mirada sobre la historiografía inglesa actual y siendo usted uno de sus representantes, ¿podría decirnos cómo debe ser aprehendida su obra, si hay una clave para su lectura teniendo en cuenta, valga la comparación, que a Platón se lo puede leer como en pequeñas cajas chinas, que a Maquiavelo se lo debe leer en zig-zag?... ¿Peter Burke debe ser leído cronológicamente?, ¿se debe agrupar su producción por temas? En este mundo cambiante, ¿ha modificado lo que proponía en sus primeras obras?

Para mí es tan importante la visión por dentro como la visión por fuera de mi obra; tal vez alguien desde fuera tenga la llave para leerme, más que yo mismo. Pero, mirando mi obra, es la clave cronológica la que me parece más fácil para poder comprenderla. ¿Por qué hacer la historia del Renacimiento italiano? Porque no quería hacer historia política, porque en aquella época todos hacían historia política, tampoco quería hacer una pura historia interna del Renacimiento sino una historia social; era la época de Raymond Williams. En 1968, Williams había publicado Cultura y sociedad, entonces yo escogí el título Cultura y sociedad en el Renacimiento. Era una especie de homenaje a R. Williams.

Escribiendo ese libro sobre la historia social de la cultura alta descubrí la ausencia de la cultura popular, y también escribiendo un libro general sobre el Renacimiento italiano, no era posible ni necesario ir a los archivos, porque muchas fuentes primarias ya estaban impresas, entonces en reacción contra eso quise hacer trabajo de archivo, por eso escogí Venecia y Amsterdam. Empezé con Venecia; es decir, Italia. Queriendo hacer una historia comparativa, y pensando en el modelo Marc Bloch, me interrogué: ¿qué ciudad puede yuxtaponerse con Venecia en el siglo XVII? Amsterdam, parecía obvio. Este era otro trabajo de elites, pero no solamente de historia cultural, era historia total de un grupo estrecho. Finalmente, escribí la Cultura popular, ya que todo proyecto, en cierto modo, es una respuesta a los puntos débiles de un proyecto interior. ¿Qué hacer después de la Cultura popular? Estudiar con más precisión la circularidad entre cultura alta y cultura baja, por eso escribí ensayos de Historia antropológica o Antropología histórica. Y luego, 
siguiendo siempre con Italia, ¿qué hacer? He vuelto al Renacimiento con una visión más global: será la segunda vez que escriba sobre la Europa en su totalidad: una vez la cultura popular, otra vez el Renacimiento. En cierto sentido, será un círculo.

¿Cómo surgió su interés por estudiar y adscribir a la Historia cultural; y, en este marco, a qué se debe la interrogación con que titula su Seminario de la Maestría en Historia - ¿ ¿Hacia una nueva historia de la cultura?»-; es que, como con la historia política, podríamos hablar de un renacer de la historia cultural?

¿Por qué historia cultural? En primer lugar porque pensé hacer carrera como pintor o como restaurador en los museos, siempre sentí una gran atracción por la cultura visual. Como académico, como historiador, pensé al menos en hacer la historia de las artes y después, como hijo de los años sesenta, sentí el impulso de escribir y de no hacer solamente historia de elites. En aquel momento en Inglaterra surgió un proyecto colectivo muy interesante: Culture Studies, una vuelta, sobre todo de críticos literarios, para estudiar la cultura popular contemporánea, aquí encontramos a Raymond Williams y luego a Stuart Hall, tal vez la cabeza más teórica de ese grupo. Ahora me siento más distanciado de ese abordaje, porque la carrera de Culture Studies en Inglaterra tuvo mucho éxito, fue imitada en otros lugares como en Australia y hoy en Italia, pero de otro lado, el proyecto hoy por hoy me parece demasiado estrecho: estudios culturales sin la historia o historia sólo del siglo XIX, y también estudios culturales sin cultura alta. Es decir, hay grandes contrastes con el proyecto de Aby Warburg, porque él no excluyó la cultura popular; en cambio, Culture Studies hoy está excluyendo a la cultura alta.

Pero es importante llamar la atención con respecto a la historia política, en primer lugar, la tendencia reaccionaria de hacer la vieja historia, y en segundo lugar, la que postula por qué no aprender algo de la antropología política, escribir historia política de estilo antropológica. Hay un libro de Annie Kriegel sobre una antropología del partido comunista francés, muy interesante, porque ella estaba dentro de ese partido, y después de salir escribió su antropología, me gustaría ver una antropología de la cámara de diputados inglesa, porque tiene unos rituales y una historia diplomática de estilo antropológica, las reglas, los rituales... Precisamos integrar la historia política en la nueva historia.

Una herencia problemática de la historia cultural reside en la forma de concebir las relaciones entre los poderes sociales y los niveles culturales. ¿Cuál es su posición actual frente al binomio cultura popular - cultura de elites?

Concuerdo con casi todos los investigadores en pensar que la circularidad entre cultura popular y cultura de elites es casi siempre muy importante. Pero, a mi ver es casi imposible analizar esa circularidad sin el binomio cultura popular cultura alta. Quizás es más útil usar el plural; tal vez en casi todas las situaciones 
históricas es mejor utilizar culturas populares - culturas altas, y no decir historia de la cultura sino historias de las culturas. Hay partes del mundo donde la interferencia política con la cultura es, o menos importante o menos obvia. En Inglaterra, tenemos la ventaja -o tal vez desventaja- que existe menos contacto entre el gobierno y la cultura -sea alta o popular- lo cual implica: menos subvenciones pero también menos censura. Por eso, mi posición parece muy inocente fuera de mi contexto inglés. Tal vez nuestra felicidad resida en no tener que pensar, en nuestra isla, en esos problemas.

En torno al binomio cultura popular - cultura de elite, le propongo un diálogo imaginario con Roger Chartier...

Existen por lo menos dos puntos de vista. Podemos escribir la historia cultural empezando con objetos culturales, textos, imágenes, prácticas: ese es el método Chartier. Siguiendo esa pista, es claro que Chartier tiene razón al decir que no podremos asociar ciertas imágenes o textos con ciertos grupos sociales; hay una migración de objetos, por lo que es siempre importante distinguir los usos. Pero hay otro punto de vista que empieza por los grupos sociales, preguntándose sobre la lógica de la apropiación, la lógica subyacente a los usos. Desde mi punto de vista, la estratificación cultural cambia. Chartier tiene razón acerca de la no estratificación social de los objetos culturales, pero tendría que tener en cuenta la estratificación de los usos culturales.

En esta línea de diálogos imaginarios, si debiera situarse en el contexto historiográfico de los estudios culturales ¿de quién se ubicaría más cerca, de Darnton, de Ginzburg, de Levi, de Chartier...?

La pregunta es muy interesante para mí, sobre todo porque no existen grandes nombres. Natalie Zemon Davis [Sociedad y cultura en la Francia moderna] merece la misma atención que Keith Thomas [Religion and the Decline of Magic]. Resulta difícil ubicarme: formamos un grupo con tantos intereses comunes, con tantos encuentros, tantos diálogos... Tengo muchas cosas en común con todos ellos, que son también mis amigos. No me siento más cerca de nadie en especial. Tal vez sea más fácil para alguien de afuera ubicarme...

Ha abordado, a lo largo del seminario, tanto conceptualizaciones como mentalidades, la historia de la cultura material, la microhistoria, y siempre alertando que se trata de conceptos sobre los que no podemos discutir eternamente. ¿En qué momento de la reflexión se encuentra usted hoy?

De antemano, me gustaría decir que para los historiadores ingleses yo estaría situado muy cerca de la filosofía, y para los historiadores europeos o america- 
nos yo soy casi un empirista. Siempre mi intención es hallar el equilibrio entre lo concreto y lo abstracto, y entre las ideas nuevas y las tradiciones culturales, porque no tengo nada contra los progresos en función de los cuales cada generación tiene que pensar la tradición. Con respecto a la microhistoria he aprendido mucho de Giovanni Levi, pero no puedo compartir su posición enteramente. Desde mi punto de vista, Levi niega la variedad de las microhistorias posibles, y yo quiero hallar el equilibrio entre micro y macrohistoria, no me gusta situarme en una isla histórica, las conexiones siempre son importantes.

Con respecto a las mentalidades, la situación es muy divertida. En Inglaterra, debo defender la historia de las mentalidades, porque casi todo el mundo sospecha de ella. Pero la primera vez que me encontré con la historia de Annales, en los Estados Unidos -en la época en que Braudel consiguió su grado honorífico-, yo hablé contra las mentalidades, reflexioné sobre la revolución historiográfica francesa diciendo que la historia francesa de las mentalidades tiene una herencia ambigua, la herencia de Lévy-Bruhl, la herencia del evolucionismo, la idea de mentalidad prelógica. Entonces podría decirse que yo tenía dos caras: una para los ingleses, otra para los franceses, pero siempre quise hallar un equilibrio. Hoy, ante la posición de Jacques Revel, no tan a favor de las mentalidades, tal vez deba defender la historia de las mentalidades en Francia y criticarla en Inglaterra.

En Hablar y callar postula a la historia social del lenguaje como intento de reconocer un terreno que la próxima generación podrá sin duda cultivar más intensivamente. Pero ¿de qué hablamos cuando hablamos de una historia social del lenguaje?

Mi objetivo es integrar el lenguaje en la historia social, e integrar el aspecto social en la historia del lenguaje. Mi inspiración fue la sociolinguística o sociología del lenguaje, o la etnografía del hablar o la etnografía de la comunicación, porque no pertenezco a ninguna escuela específica y hay varias escuelas entre los lingüistas de hoy. Quería hacer un puente entre lingüistas e historiadores. Claro que puede parecer un poco atrasado hablar, en los años noventa, de una historia social del lenguaje como de una historia social del arte, pero en la introducción a ese libro intenté mostrar que hay una influencia de la sociedad en el lenguaje, pero también una influencia del lenguaje en la sociedad, de nuevo intentando establecer un equilibrio entre fuerzas intelectuales opuestas, queriendo realizar una síntesis provisoria, teniendo en cuenta que toda síntesis intelectual es provisoria. Desgraciadamente hasta ahora, muy pocos historiadores, por lo menos que yo sepa, están siguiendo esa pista, tal vez será para el siglo que viene.

En relación con lo antedicho, ¿qué diferencia hay entre una historia social del lenguaje y el estudio foucaultiano de las formaciones histórico-discursivas, si tene- 
mos en cuenta que en función de estudios realizados sobre épocas en las que no podemos auxiliarnos con la historia oral, debemos recurrir a una «oralidad escrita»?

Me gustaría dividir la respuesta en dos apartados. El primero tiene que ver con las fuentes. Creo que podemos utilizar fuentes literarias como las novelas, siempre recordando que esos textos no son espejos sino estilizaciones de la lengua hablada, claro que en el futuro con la historia oral -que ya tiene más de treinta años-, un banco de datos no utilizado en la historia del lenguaje lo podremos utilizar en ese proyecto también. La segunda respuesta, sobre la relación entre los discursos tal vez en el sentido más literal, más estrecho del lingüista, y el discurso en el sentido más metafórico foucaultiano, me lleva a pensar que no es fácil ver una conexión aunque debe haberla. Desde mi punto de vista, lo interesante será hacer un abordaje sociolingüístico para el discurso del propio Foucault, con las preguntas normales para los sociolingüistas: ¿Quién habla a quién?, ¿diciendo qué?, ¿con qué registros, medios de comunicación?, ¿con qué intenciones? y, eventualmente, ¿con qué resultados? Ya que, desde mi punto de vista, no solamente se ha de ver el discurso de Foucault como suspendido en el aire. Él sabía de lo social, pero no quería hablar de eso; no era falta de conciencia, sino de voluntad.

Retomando la cita de Ortega y Gasset que encabeza uno de los capítulos de su reciente publicación en habla castellana-«el discurso consiste sobre todo en el silencio»-, así como el objetivo que usted persigue en la construcción de una historia social del silencio, en la Europa moderna temprana, ¿cómo esbozaría la historia de las cambiantes significaciones que tuvo el silencio?

¿Por qué hacer ese proyecto paradojal? En primer lugar, me atraía descubrir los límites de la investigación histórica. Hoy estamos viendo una gran expansión del territorio del historiador; entonces, ¿cuáles son las fronteras? El único medio de saberlo es explorar esos límites. En segundo lugar, la inspiración provenía de la lectura de artículos de los antropólogos. Hay uno, muy interesante, de Keith Basso, sobre el silencio de los apaches, tribu a la que no le gusta hablar mucho; aquí podríamos preguntarnos: ¿es posible viajar un día para ver a un amigo, llegar y no hablar? ¿Por qué no hablar? Porque el motivo era ver al amigo, no hablar de uno u otro asunto. Entonces, para Basso, era un proyecto explicar cómo para un grupo el silencio tiene un sentido y para otro grupo tiene otro. Así, mi idea era investigar el pasado pensando en esto precisamente y teniendo en cuenta, por ejemplo, que en la época del dramaturgo Harold Pinter todos consideraban que, en su teatro, los silencios eran más importantes que las palabras.

¿Qué recomendaría a los investigadores que actualmente se están formando en un territorio tan complejo como es el de la historia cultura?:Qué no se debe 
dejar de leer?, ¿qué centros de estudios se debieran conocer?, ¿qué «pistas» se deben seguir?, ¿cuál es su exhortación para quienes estamos construyendo el «oficio de historiador»?

Esta pregunta es también muy difícil. Recuerdo en estos momentos que, cuando entrevisté a Braudel, mi gran orgullo fue cuando él me dijo «iUd. me formula preguntas terribles!». En primer lugar, puedo decir que se puede empezar en cualquier sitio, eso no tiene importancia. Luego, un consejo muy braudeliano: es siempre fundamental situar el tema escogido en un contexto o, mejor, en varios contextos, hasta llegar al contexto global. Es muy importante no encerrarse en una investigación; hay que mirar las conexiones entre ese tema, esa aldea y esa persona y las cosas más grandes. Por otra parte, hoy, en la época de la globalización historiográfica, es más difícil recomendar París, Princeton o Bielefeld... Es imprescindible no encerrarse en una lengua, en una mentalidad. Así, para la formación de un buen historiador del siglo XXI, será muy importante aprender lenguas, viajar, saber escuchar, y entrar en discursos historiográficos de tradiciones muy diversas.

En cuanto a las lecturas, no sólo se deben leer los libros más apreciados dentro de la nueva historia; claro que es imposible no leer El Mediterráneo de Braudel, pero también es imposible dejar de lado a Burkhardt, con La Civilización del Renacimiento, o a Huizinga con El otoño de la Edad Media, si tomamos una perspectiva cultural. Ahora, como historiador de la política, conozco mejor la historiografía de mi país, por lo que creo interesante proponer la lectura de Lewis Namier, que no es inglés, sino más inglés que los ingleses, pero hizo un estudio pionero sobre la estructura política de Inglaterra en el siglo XVIII, gran obra desmitificante, donde afirmaba que detrás de las fachadas de los partidos políticos existe una realidad mucho más clientelística.

¿Podría expresar su opinión acerca de la función del historiador para el siglo XXI?

Tal vez valga la pena tomar la posición de historiador de la cultura, diciendo que no es el único rol importante, pero destacándolo. El papel de la historia de la cultura es, en una frase, «hacer la traducción cultural». Precisamos cada vez más de la traducción cultural y del entendimiento entre gentes de culturas diversas. En estos momentos de resurgimiento de los nacionalismos, y también porque es una época de cambios tan rápidos, precisamos más y más de una traducción cultural entre el pasado y el presente. Desde mi punto de vista, éste es en el futuro, el gran papel para nosotros, los historiadores de la cultura. 


\section{BIBLIOGRAFÍA}

Peter Burke ha trabajado sobre ciertos aspectos singulares de la época renacentista y sobre la cultura popular moderna. Así se refleja en su The Renaissance Sense of the Past (Londres, Arnold, 1969); en una obra influyente, La cultura popular en la Europa moderna (Madrid, Alianza, 1996; or. 1978); así como en su monografía sobre Montaigne (Alianza, 1985; or. 1981) o, desde luego, en varios libros sobre la Italia de esa época inaugural de la modernidad: El Renacimiento italiano. Cultura y sociedad en Italia (Alianza, 1993; or. 1972 y 1986); Historical Anthropology of Earl Modern Italy (Cambridge, 1987); Los avatares de 'El cortesano'. Lectura e interpretaciones de uno de los libros más influyentes del Renacimiento (Barcelona, Gedisa, 1998; or. 1995); El Renacimiento (Barcelona, Crítica, 1999; or. 1987). Más recientemente ha publicado El Renacimiento europeo. Centros y periferias (Crítica, 2000; or. 1998), así como la reunión de artículos Formas de historia cultural (Alianza, 2000; or. 1997).

Por otra parte, Peter Burke se ha ocupado en muchos textos de la historiografía del presente, con especial interés por la renovación francesa. Se han traducido al castellano: Sociología e historia (Alianza, 1987; or. 1980); La revolución historiográfica francesa. La Escuela de los Annales, 19291989 (Gedisa, 1993; or. 1990); una publicación colectiva, que recoge importantes contribuciones historiográficas de los ochenta: Formas de hacer historia (Alianza, 1994; or. 1991); y su último balance: ¿Qué es la historia cultural? (Paidós, 2006; or. 2004).

A todo ello se añaden libros tan singulares como La fabricación de Luis XIV (Madrid, Nerea, 1995; or. 1992); Venecia y Amsterdam. Estudios sobre las élites del siglo XVII (Gedisa, 1996; or. 1974 y 1994); Hablar y callar. Funciones sociales del lenguaje a través de la historia (Gedisa, 1995; or. 1993); y Visto y no visto. El uso de la imagen como documento histórico (Crítica, 2001; or. 2001). En los últimos años ha estudiado especialmente la recopilación y difusión del conocimiento en la moderna Europa: Historia social de conocimiento, de Gutenberg a Diderot (Paidós, 2002; or. 2000), y Una historia social de los medios de comunicación (Madrid, Taurus, 2002, responsable con Asa Briggs; or. 2002). Finalmente, Lenguas y comunidades en la Europa moderna (Madrid, Akal, 2006).

* Esta entrevista fue concedida por Peter Burke a Claudia Möller en ocasión de su primera visita a la Argentina, como historiador, en diciembre de 1996, invitado por el Programa de Maestría en Historia de la Facultad de Humanidades, de la Universidad Nacional de Mar del Plata. Claudia Möller Recondo es Doctora en Historia por la Universidad de Salamanca. 